\title{
Artificial Neural Network Modelling of Photodegradation in Suspension of Manganese Doped Zinc Oxide Nanoparticles under Visible-Light Irradiation
}

\author{
Yadollah Abdollahi, ${ }^{1,2}$ Azmi Zakaria, ${ }^{1}$ Nor Asrina Sairi, ${ }^{2}$ Khamirul Amin Matori, ${ }^{1}$ \\ Hamid Reza Fard Masoumi, ${ }^{3}$ Amir Reza Sadrolhosseini, ${ }^{4}$ and Hossein Jahangirian ${ }^{5}$ \\ ${ }^{1}$ Material Synthesis and Characterization Laboratory, Institute of Advanced Technology, Universiti Putra Malaysia, \\ 43400 Serdang, Selangor, Malaysia \\ ${ }^{2}$ Chemistry Department, Faculty of Science, University of Malaya, 50603 Kuala Lumpur, Malaysia \\ ${ }^{3}$ Department of Chemistry, Faculty of Science, University Putra Malaysia, 43400 Serdang, Selangor, Malaysia \\ ${ }^{4}$ Wireless and Photonics Networks Research Center (WiPNET), Faculty of Engineering, Universiti Putra Malaysia, Serdang, Malaysia \\ ${ }^{5}$ Department of Chemical and Environmental Engineering, Faculty of Engineering, Universiti Putra Malaysia (UPM), \\ 43400 Serdang, Selangor, Malaysia \\ Correspondence should be addressed to Yadollah Abdollahi; yadollahabdollahi@yahoo.com
}

Received 17 March 2014; Revised 30 July 2014; Accepted 8 September 2014; Published 4 November 2014

Academic Editor: J. Paul Chen

Copyright ( 2014 Yadollah Abdollahi et al. This is an open access article distributed under the Creative Commons Attribution License, which permits unrestricted use, distribution, and reproduction in any medium, provided the original work is properly cited.

\begin{abstract}
The artificial neural network (ANN) modeling of $m$-cresol photodegradation was carried out for determination of the optimum and importance values of the effective variables to achieve the maximum efficiency. The photodegradation was carried out in the suspension of synthesized manganese doped $\mathrm{ZnO}$ nanoparticles under visible-light irradiation. The input considered effective variables of the photodegradation were irradiation time, $\mathrm{pH}$, photocatalyst amount, and concentration of $m$-cresol while the efficiency was the only response as output. The performed experiments were designed into three data sets such as training, testing, and validation that were randomly splitted by the software's option. To obtain the optimum topologies, ANN was trained by quick propagation (QP), Incremental Back Propagation (IBP), Batch Back Propagation (BBP), and Levenberg-Marquardt (LM) algorithms for testing data set. The topologies were determined by the indicator of minimized root mean squared error (RMSE) for each algorithm. According to the indicator, the QP-4-8-1, IBP-4-15-1, BBP-4-6-1, and LM-4-10-1 were selected as the optimized topologies. Among the topologies, QP-4-8-1 has presented the minimum RMSE and absolute average deviation as well as maximum R-squared. Therefore, QP-4-8-1 was selected as final model for validation test and navigation of the process. The model was used for determination of the optimum values of the effective variables by a few three-dimensional plots. The optimum points of the variables were confirmed by further validated experiments. Moreover, the model predicted the relative importance of the variables which showed none of them was neglectable in this work.
\end{abstract}

\section{Introduction}

According to the last report of united nation world water development, most untreated industrial wastewater which contains several kinds of organic pollutants such as phenolic compounds is flowing into the productive lands, surface, and underground water sources [1]. To prevent the hazardous materials from entering into the environment, the effective and environmental compatibility removal methods are attracting the attentions. Therefore, several chemical, physical, and biological methods have been applied to remove the pollutants by using chemical coagulation, oxidation, flocculation, precipitation, froth floatation, reverse osmosis, and biological techniques $[2,3]$. However, the chemical methods are unable to mineralize all the organics and also generate new environmental pollutants [4]. In the same trend, the biological methods are slow, selective, $\mathrm{pH}$, and temperature sensitive $[5,6]$. The physical methods such as 
adsorption techniques are unable to remove the hazardous from the environment. On the other side, advanced oxidation processes (AOPs) such as heterogeneous photocatalytic processes including photocatalyst, Fenton, photo-Fenton, and electrooxidation are powerful and nonselective methods that have been used to convert the persistent organic pollutants to an environmental friendly product [7-9]. Among the various AOPs methods, the heterogeneous photocatalytic process has been succeed due to its ability for destroying a wide range of the pollutants at ambient temperature and pressure without generation of harmful intermediates [1017]. The processes use a catalyst that is active under UV or visible-light irradiation to generate hydroxyl radical [18]. Zinc oxide $(\mathrm{ZnO})$ is well-known nontoxic semiconductor materials that has been used as heterogeneous photocatalyst to investigate water purification $[19,20]$. $\mathrm{ZnO}$ has facilitated several degradations of the water organic contaminants under UV irradiation [21, 22]. In addition, the grate advantages of $\mathrm{ZnO}$ are absorption of a large fraction of the solar spectrum (sunlight) which is free and available around the world [23]. Sunlight consists of $47 \%$ visible-light with wavelength of 400 to $700 \mathrm{~nm}$ or energy of 1.77 to $2.76 \mathrm{eV}$. Thus, visible-light could be an excellent source of energy for the photocatalytic activity. However, the photo activity of $\mathrm{ZnO}$ under the energy was very low due to its high direct band gap energy, $3.2 \mathrm{eV}[19,20]$. Therefore, several methods of synthesis have been examined to improve the band gap such as transition metals doped $\mathrm{ZnO}$ [24-29]. As the absorption spectra red shift has showed, the $3 \mathrm{D}$ orbital of the metals goes between valence band (VB) and conduction band (CB) of the semiconductors in doping process $[30,31]$. It depends on the energy of the $3 \mathrm{D}$ orbitals, they overlap with the VB or CB of the semiconductors [32]. For the reason, the electrons are excited from $\mathrm{VB}$ (the $3 \mathrm{D}$ overlapped $\mathrm{VB}$ ) to $\mathrm{CB}$ (3D overlapped $\mathrm{CB}$ ) during irradiation process. On the other hand, the energy of manganese (Mn) $3 \mathrm{D}$ orbitals is very close to the $\mathrm{VB}$ of $\mathrm{ZnO}$ which easily overlap to decrease the $E_{g}[10,17]$. In our previous work, $\mathrm{Mn}$ doped $\mathrm{ZnO}$ was synthesized and applied for degradation of organic pollutants [29]. The photodegradation was studied by one variable at a time technique with the effective variables of irradiation times, $\mathrm{pH}$, photocatalyst amount, and concentration of the pollutants $[33,34]$. The problem is that the technique varies one of the parameters while the other terms are kept constant during the multivariate performance. Therefore, it has adverse effects on the photodegradation that should be studied by multivariate methods [17, 21]. Moreover, the kinetic determination of the process is quite complicated by consideration of the mass transfer, the radiant energy balance, the spatial distribution of the absorbed radiation, and mechanisms of the photochemical degradation [35]. The photodegradation as a process consists of input factors such as effective variables and the efficiency as output response. The changing amount of the effective variables affects the value of the efficiency. Therefore, the amount of the variable could be optimized to achieve the maximum efficiency that is free of the mentioned complexities. The known multivariate methods that used to optimize the productive process included response surface methodology (RSM) and artificial neural network (ANN) $[35,36]$. The RSM designs the related experiments and then fits the observed results of performed design to appropriate polynomial and suggests the qualified model for more validation. The model as a mathematic equation indicates the relationships between variables themselves, variables and response(s). Thereafter, the validated model is used to optimize the effective variables to achieve the maximum yield of the products. However, the method is involved with the complicated statistical calculation such as analysis of variance, fitting, and regression process for modeling process $[37,38]$. On the other hand, ANNs have been widely used for modeling of chemical and biochemical reaction process [39-43]. The ANN modeling has been reliable, robust, and salient characteristics in capturing the nonlinear relationship between the input and output variables which is free of complexities. In this work, the multilayer feed-forward neural network was used to model $m$-cresol photodegradation in manganese doped $\mathrm{ZnO}$ nanoparticles ( $\mathrm{Mn}$ doped $\mathrm{ZnO} \mathrm{NPs}$ ) suspension under visible-light irradiation. The cresol is widely used in several manufacturing products with high water solubility which has been listed as priority pollutants, persistent toxic chemical, and a significant threat to the environment $[44,45]$. The input effective operational parameters were including irradiation time, $\mathrm{pH}$, photocatalyst amount, and concentration of the cresol while the efficiency \% was the only response as output.

\section{Materials and Methods}

The chemicals of this work were obtained from Merck and were used without further purification. The $m$-cresol $(99 \%)$ was used as organic water pollutant while $\mathrm{H}_{2} \mathrm{SO}_{4}(95 \%-97 \%)$ and $\mathrm{NaOH}$ (99\%) were applied to set the appropriate $\mathrm{pH}$. The $\mathrm{Mn}$ doped $\mathrm{ZnO}$ NPs with average particles size $35 \mathrm{~nm}$, bang gap energy, $2.2 \mathrm{eV}$, and surface area $35 \mathrm{~m}^{2} \mathrm{~g}^{-1}$ were used as photocatalyst. The photocatalyst was synthesized by precipitation method in absolute alcohol according to our published work [29]. To degrade the pollutant, the various concentrations of $m$-cresol were mixed with appropriate amount of the photocatalyst in $500 \mathrm{~mL}$ deionized water. The mixture (suspension) solution was irradiated by a Philips lamp (23 watts) as light source in a batch homemade photoreactor that was used in our previous work [46]. The suspension was magnetically stirred during the irradiation at $200 \mathrm{rpm}$. Moreover, air was blown into the solution by using an air pump at a flow rate of $150 \mathrm{~mL} / \mathrm{min}$ to increase solution fluidization, access oxygen, volatile the produced gas $\left(\mathrm{CO}_{2}\right)$, and keep the temperature at around $25^{\circ} \mathrm{C}$. During the performance, samples were withdrawn from the bulk solution at specific time intervals and centrifuged at $14000 \mathrm{rpm}$ for $20 \mathrm{~min}$ and then they filtered through $0.2 \mu \mathrm{m}$ PTFE filter to measure the remained concentration of the $m$-cresol. The measurement was carried out by a Shimadzu UV-1650 PC and a TOC-VCSN analyzer, respectively. In addition, the initial catalyst absorption and photocatalyst were investigated in dark and absence of the photocatalyst at normal $\mathrm{pH}$ (7.5) that were considered in the efficiencies calculation [47]. The efficiencies were used as actual responses for modeling of the photodegradation which was carried out by Neural Power Software version $2.5[48,49]$. The total of 31 experiment 
TABLE 1: The training, testing, and validation data sets of the effective variables and actual and models predication efficiency of $m$-cresol photodegradation by Mn doped ZnO NPs.

\begin{tabular}{|c|c|c|c|c|c|c|}
\hline \multirow{2}{*}{ Run } & \multirow{2}{*}{ Irradiation time } & \multirow{2}{*}{$\mathrm{pH}$} & \multirow{2}{*}{ Photocatalyst } & \multirow{2}{*}{$m$-cresol } & \multicolumn{2}{|c|}{ Efficiency } \\
\hline & & & & & Actual & Predicted \\
\hline \multicolumn{7}{|c|}{ Training data set } \\
\hline 1 & 360 & 7.63 & 1.5 & 65 & 38.9 & 37.057 \\
\hline 2 & 120 & 7.63 & 1.5 & 35 & 30.86 & 30.435 \\
\hline 3 & 360 & 4 & 1.5 & 35 & 46.4 & 46.457 \\
\hline 4 & 360 & 10 & 1.5 & 35 & 48.7 & 48.922 \\
\hline 5 & 360 & 7.63 & 3 & 35 & 83.7 & 84.001 \\
\hline 6 & 360 & 7.63 & 1.7 & 35 & 95 & 95.864 \\
\hline 7 & 240 & 7.63 & 1.5 & 35 & 65.08 & 66.073 \\
\hline 8 & 360 & 8.5 & 1.5 & 35 & 89.3 & 90.323 \\
\hline 9 & 360 & 6 & 1.5 & 35 & 67.2 & 68.333 \\
\hline 10 & 360 & 8 & 1.5 & 35 & 93.4 & 94.741 \\
\hline 11 & 360 & 7.63 & 1 & 35 & 79.9 & 81.33 \\
\hline 12 & 300 & 7.63 & 1.5 & 35 & 81.42 & 82.96 \\
\hline 13 & 360 & 7.63 & 1.5 & 55 & 46.80 & 49.625 \\
\hline 14 & 360 & 7.63 & 3.5 & 35 & 72.4 & 80.016 \\
\hline 15 & 360 & 7.63 & 1.5 & 15 & 100 & 109.16 \\
\hline \multicolumn{7}{|c|}{ Testing data set } \\
\hline 17 & 360 & 9 & 1.5 & 35 & 72.7 & 79.504 \\
\hline 18 & 360 & 7.63 & 0.5 & 35 & 50.2 & 64.026 \\
\hline 19 & 360 & 7.63 & 1.5 & 41 & 81.6 & 74.845 \\
\hline 20 & 360 & 7.63 & 1.3 & 35 & 94.2 & 88.926 \\
\hline 21 & 360 & 7.63 & 1.5 & 30 & 99.2 & 97.703 \\
\hline 22 & 360 & 7.63 & 1.5 & 25 & 100 & 99.572 \\
\hline 23 & 360 & 7.63 & 2.5 & 35 & 87.9 & 90.131 \\
\hline 24 & 60 & 7.63 & 1.5 & 35 & 12.48 & 17.993 \\
\hline \multicolumn{7}{|c|}{ Validation data set } \\
\hline 26 & 360 & 7.63 & 1.5 & 45 & 73.3 & 62.789 \\
\hline 27 & 360 & 7.63 & 1.5 & 35 & 98.98 & 91.939 \\
\hline 28 & 360 & 7.63 & 1.5 & 76 & 32.5 & 28.915 \\
\hline 29 & 180 & 7.63 & 1.5 & 35 & 47.55 & 46.747 \\
\hline 30 & 360 & 5 & 1.5 & 35 & 50.8 & 52.441 \\
\hline 31 & 360 & 7.63 & 2 & 35 & 93.2 & 94.923 \\
\hline
\end{tabular}

points have been randomly splitted into training (15 points), testing (8 points) and validation (6 points) data sets (Table 1$)$ by using the facilitated option in the software. The training was used to compute and ensure robustness of the network parameters while the testing stage was used as control errors to avoid overfitting [50]. The validation data which was excluded from training and testing considered to assess the predictive ability of the generated model [51].

\section{Theory of the Work}

3.1. The Theory of ANN. ANNs are semiempirical multivariate methods that are used in mathematic free fictionalization of the complicated productive process. The networks contain input, hidden, and output layers which are made of several nodes. The nodes are connected by multilayer normal feedforward or feed-back connection formula [52]. The nodes are simple artificial neurons which stimulates the behavior of biological neural networks. The hidden layer could be more than one parallel layer however the single hidden layer is universally suggested. In the network, the nodes of particular layer are connected to the nodes of the next layer from left to right by feed-forward formula. The nodes of input layer are qualified by sending data via the special weights to the nodes of hidden layer and then to the output layer $[52,53]$. The qualification is carried out by associated weights during learning process by well-known mathematic algorithms.

3.2. The Learning Process. The learning process determines the number of nodes in the hidden layer (topology) by using trial and error calculation. The calculation is examined from one to " $n$ " nodes to discover the architecture with minimum root mean square error (RMSE) by using testing data set and particular algorithm. In learning process, the input layer acts 
as distributor for the hidden layer and the inputs and output of the hidden layer are multiplied by weighted summation as follows:

$$
S=\sum_{i=1}^{n h}\left(b-W_{i} I_{i}\right)
$$

where $S$ is summation, $b$ is a bias [54], $I_{i}$ is the $i$ th input to hidden neuron, and $W_{i}$ is the weight associated with $I_{i}$. The bias shifts the space of the nonlinearity properties [55]. Therefore, the outputs of the hidden layer act as inputs to final layer (output) which are undergoing a transfer function. The popular transfer function is the logarithmic sigmoid for both hidden and output layers that is bounded from 0 to 1 [56]. The sigmoid bounded area is used to normalize the input and output data that is provided by the software scaling. The scaled data are passed into the first layer and propagated to hidden layer and finally meet the output layer of the network by iterative procedure. The iteration is an act of repeating a process to approach a desire result. The results of iteration are used as starting point of next iteration. For example, when the results of last iteration become almost equal to the results of previous iteration, the process will be terminated. The iteration process is continued by self-similarity method as follows [57]:

$$
S(B)=\sum_{I=1}^{m}\left[y_{i}-f\left(x_{i} \beta\right)^{2}\right],
$$

where " $m$ " is an empirical data pairs of independent and dependent variables such as $\left(x_{i}, x_{i}\right)$ and $f\left(x_{i}, \beta\right)$ is the model curve. In self-similarity process, the $\beta$ parameter of $f\left(x_{i}, \beta\right)$ is optimized by minimizing the sum of the squares. As a result, the main aim of the learning process is to find the weights for minimizing the error of (RMSE) which is obtained from difference between network prediction and actual responses as follows:

$$
\mathrm{RMSE}=\left(\frac{1}{n} \sum_{i=1}^{n}\left(y_{i}-y_{d i}\right)^{2}\right)^{1 / 2}
$$

where " $n$ " is number of the points, $y_{i}$ is the predicted values, and $y_{d i}$ is the actual values. To avoid random correlation due to the random initialization of the weights, the examination of each node is repeated several times. Among the repeated examination, the architecture with lowest RMSE is selected for each node. The RMSE of the architectures are compared to find the best topology for the particular algorithm. The topology is architecture with minimum relative RMSE. For more certainty, the $R$-square $\left(R^{2}\right)$ (see $\left.(4)\right)$ and absolute average deviation (AAD) (see (5)) are calculated by performance of the topology for training and testing data sets:

$$
\begin{gathered}
R^{2}=1-\frac{\sum_{i=1}^{n}\left(y_{i}-y_{d i}\right)^{2}}{\sum_{i=1}^{n}\left(y_{d i}-y_{m}\right)^{2}} \\
\mathrm{AAD}=\frac{1}{n} \sum_{I=1}^{n} \frac{\left|y_{i}-y_{d i}\right|}{y_{d i}},
\end{gathered}
$$

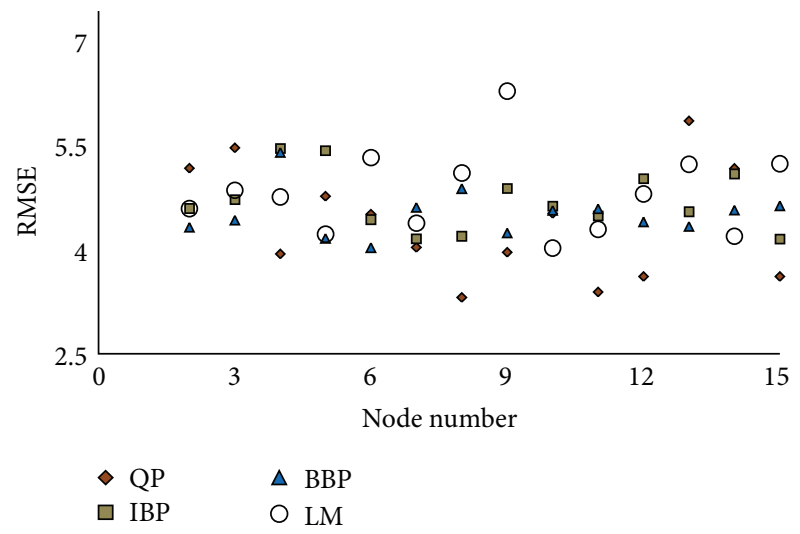

FIGURE 1: The selected RMSE versus node number of the photodegradation network's hidden layer for QP, IBP, BBP, and LM algorithm. The smallest RMSE belong to node of 8 (QP), 15 (IBP), 6 (BBP) and 10 (LM).

where " $n$ " is the number of points, $y_{i}$ is the predicted value, $y_{d i}$ is the actual value, and $y_{m}$ is the average of the actual values. The learning process is carried out for different algorithms to obtain the best topology. Then the RMSE, $\mathrm{AAD}$, and $R^{2}$ of the topologies are compared to find the optimized topology that is selected as provisional model for the process. The model is evaluated by validation data set (Table 1). Thereafter, it is used for navigation of the process that determines the optimum and importance of the input variables to maximize the yield of the process.

\section{Results and Discussion}

4.1. The Modeling Process. The network of the photodegradation process contains input, hidden, and output layers which they are made of one or more number of nodes. The structure of the input and output layer was determined by number of the effective variables and the efficiency of the photodegradation while the structure of the hidden layer was determined by the modeling. The effective variables included temperature, $\mathrm{pH}$, photocatalyst amount, and concentration of $m$-cresol.

4.1.1. The Structure of the Hidden Layer. To obtain the structure of the hidden layer, 15 architectures that contained 1 to 15 nodes were examined for quick propagation (QP), Incremental Back Propagation (IBP), Batch Back Propagation (BBP), and Levenberg-Marquardt (LM) algorithms. The examination was repeated 10 times for each node by testing data set. Then, among the 10 repetitions, the architecture with the smallest RMSE was selected for each node. Therefore, 15 architectures were considered for each algorithm illustrated in Figure 1 to find the optimized topologies. Figure 1 plots the value of RMSE versus the node number for QP, IBP, $\mathrm{BBP}$, and LM algorithms. For each algorithm, one of the 15 architectures has presented minimum RMSE (topology) considered for more evaluation. The hidden layer's node numbers of selected topologies were 8, 15, 6, and 10 for QP, IBP, BBP, and LM logarithms, respectively. The evaluation of 

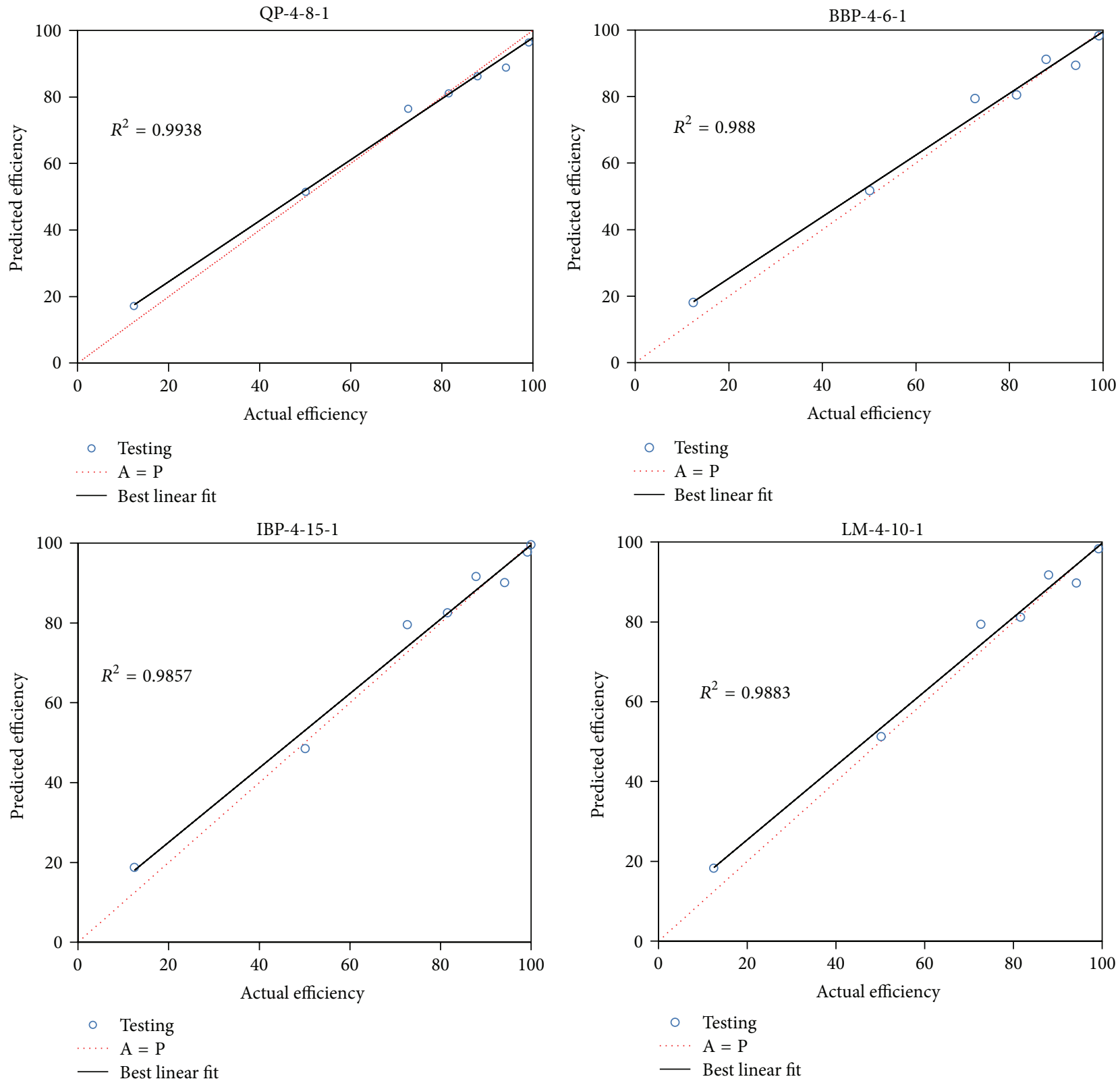

FIgURE 2: The scatter plots of the predicted efficiency versus actual efficiency for testing data set that shows the performed $R^{2}$ of optimized topologies, QP-4-8-1, BBP-4-6-1, IBP-4-15-1, and LM-4-10-1.

the topologies was carried out by comparison of minimum RMSE and AAD as well as maximum $R^{2}$ to discover the provisional model of the photodegradation. The comparison of the RMSE proved that the QP with 4 nodes in input, 8 nodes in hidden, and 1 node in output layer (QP-4-8-1) has presented the minimum root mean squared error (Figure 1).

Then, the performed results of the topologies were used to calculate $R^{2}$ (see (4)) and ADD (see (5)). To calculate the $R^{2}$, the prediction of the topologies and actual values of the efficiency were plotted for testing data set in Figure 2. As the scatter plots showed, the topology of QP-4-8-1 has presented the highest $R^{2}, 0.993$, that, in comparison with other topologies, has the best performance.
Moreover, the $\mathrm{AAD}$ of the topologies in testing data set was calculated for QP-4-8-1, IBP-4-15-1, BBP-4-6-1, and LM4-10-1 (Figure 3). As shown, the lowest value of the AAD has also belonged to topology of QP-4-8-1. As a result, the topology of QP-4-8-1 was pioneer in minimum RMSE and $\mathrm{AAD}$ as well as at maximum of $R^{2}$ among those topologies for testing data sets. Therefore, QP-4-8-1 was selected as final optimum provisional model of the photodegradation for validation test.

4.1.2. Validation of the Selected Model. The provisional model (QP-4-8-1) was validated by 6 experimental points excluded from training and testing data sets (Table 1). 


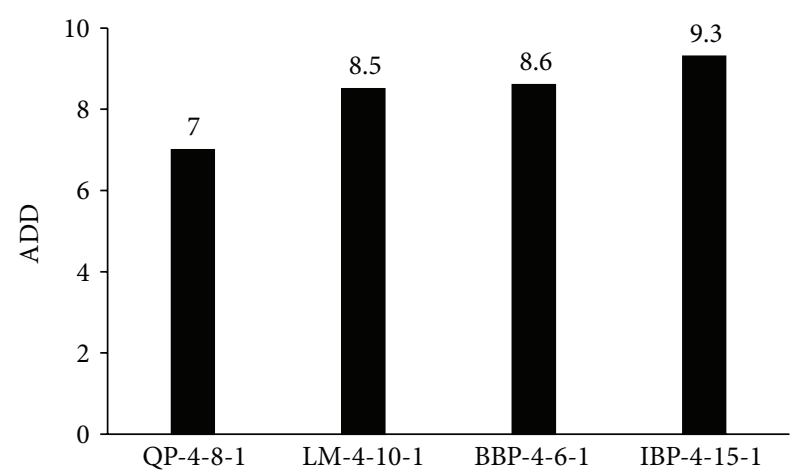

Figure 3: The AAD of QP-4-8-1, BBP-4-6-1, IBP-4-15-1, and LM-410-1 topologies in testing data set.

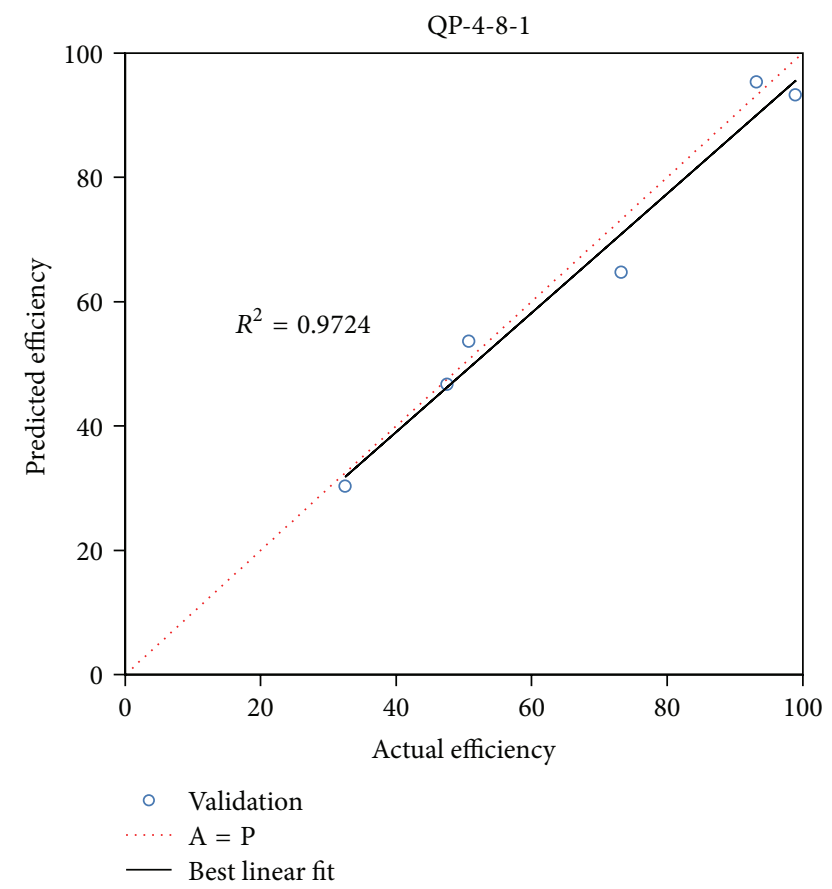

FIGURE 4: The validation test of the provisional model (QP-4-8-1) which consists of actual and predicted photodegradation efficiency as well as the best linear fit and $R$-square.

The validation was investigated by scatter plots of the model prediction versus actual values of the photodegradation efficiency (Figure 4). As demonstrated, the $R^{2}, 0.972$, of the performance was quite close to 1 that confirmed the model is significant. In addition, the RMSE and AAD of the performed validation included 4.574 and 5.668, respectively, which proved the great predictive accuracy of the model.

4.1.3. The Final Model of the Photodegradation. Figure 5 shows the structure of QP-4-8-1 topology as final model for $m$-cresol photodegradation. The model consists of three layers that included input, hidden, and output layers. The input layer with 4 nodes of effective variables acts as distributor for the hidden layer with 8 nodes. The inputs as well as output of hidden nodes are multiplied by the appropriate weights [55].

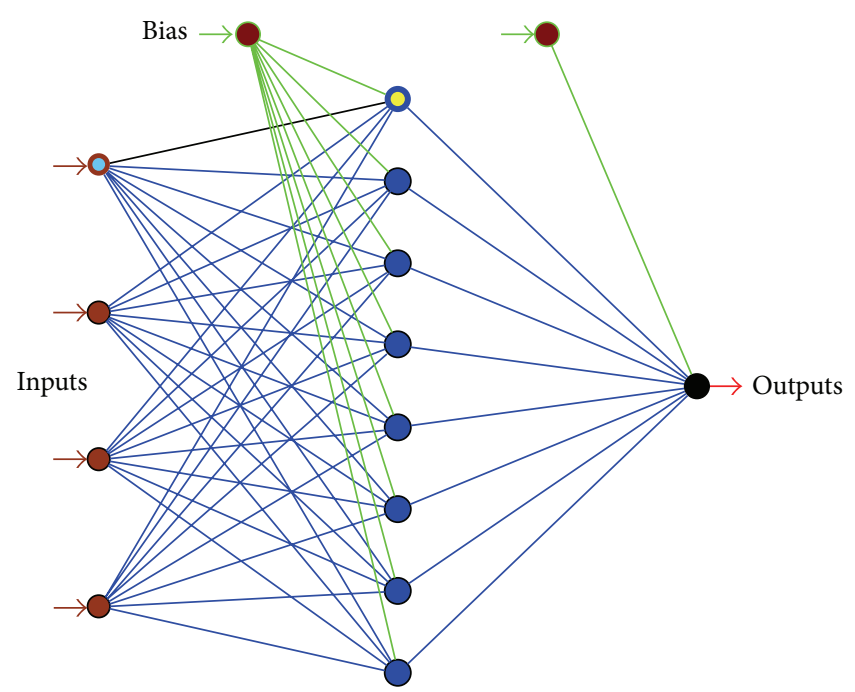

FIGURE 5: The structure of the photodegradation final model of QP4-8-1 that consists of 4 nodes in input layer, 8 nodes in hidden layer, and 1 node in output layer as response.

Then the nodes outputs of hidden layer are transferred to output layer by using log-sigmoid transfer function (see (6)) [58]. The function normalizes transfers the data between the layers [56]:

$$
f(x)=\frac{1}{1+\exp (-x)},
$$

where $f(x)$ is the hidden output neurons. Therefore, QP4-8-1 was used to navigate the process for determination of optimum and importance values of the photodegradation input variables.

4.2. The Model Applications of the Photodegradation. As a short overview, the modeling process optimized the topologies of different learning algorithms by using testing and training data sets. Then the best topology with optimum $R^{2}$, RMSE, and AAD was selected as provisional model for more evaluation. The adequacy of the selected model (QP$4-8-1)$ was evaluated by validation data set. The validation model QP-4-8-1 was used to navigate the photodegradation. The navigation has contained graphical optimization and the relative importance of the input effective.

4.2.1. The Variables Graphical Optimization. The validated model, QP-4-8-1, simulated the behavior of the photodegradation without further requirement of mathematic knowledge (Figures 6 to 8). The simulations consist of effect of nonlinear relationship of two variables on photodegradation efficiency which is graphically presented by three dimensional plots (3D) while the other parameters were kept constant at the middle of their levels' values. The values of irradiation time were $210 \mathrm{~min}, \mathrm{pH}$ was 7.5 , photocatalyst amount was $2(\mathrm{~g} / \mathrm{L})$, and concentration of $m$-cresol was $45.5(\mathrm{mg} / \mathrm{L})$.

Figure 6 shows the variation of the efficiency in $\mathrm{pH} 5$ to $\mathrm{pH} 10$ during irradiation time 60 to $360 \mathrm{~min}$ while the amount of photocatalyst and $m$-cresol were kept constant at 


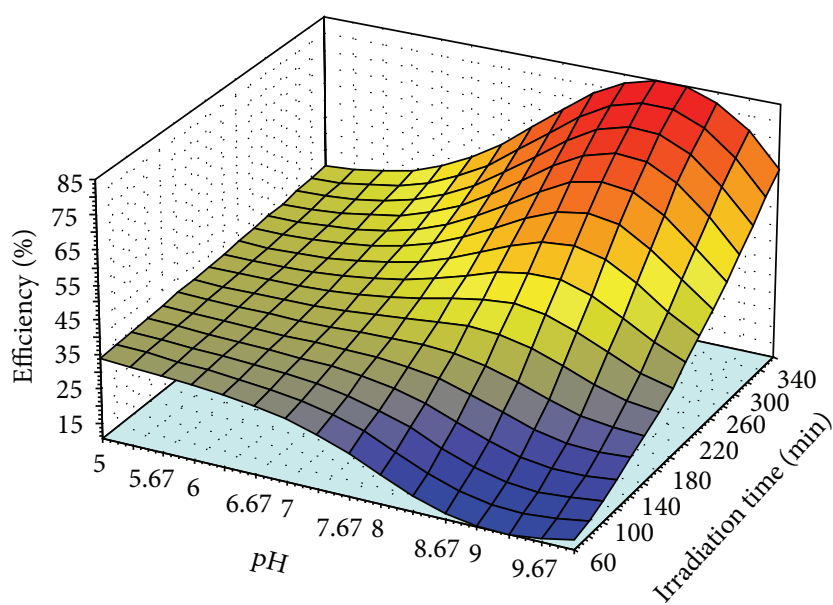

FIGURE 6: The variation of the photodegradation efficiency in $\mathrm{pH}$ 5 to $\mathrm{pH} 10$ and irradiation time (60 to $360 \mathrm{~min}$ ), the amount of photocatalyst $(2 \mathrm{~g} / \mathrm{L})$ and $m$-cresol $(45.5 \mathrm{mg} / \mathrm{L})$ were at middle of their levels.

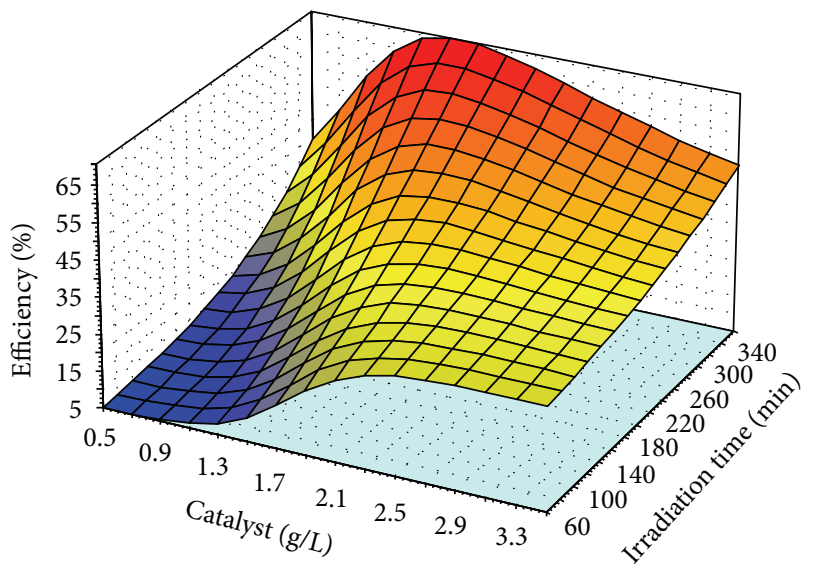

FIGURE 7: The efficiency variation of the photodegradation with varying photocatalyst from 0.5 to $3.5 \mathrm{~g} / \mathrm{L}$ and irradiation time (60-360 $\mathrm{min}$ ); the $\mathrm{pH}$ was 7.5 and $m$-cresol was $45.5 \mathrm{mg} / \mathrm{L}$.

$2 \mathrm{~g} / \mathrm{L}$ and $45.5 \mathrm{mg} / \mathrm{L}$, respectively. As shown, the efficiency was increased up to $\mathrm{pH} 9$ and thereafter it was decreased for irradiation time 300 to $360 \mathrm{~min}$. Therefore, the maximum surface of the $3 \mathrm{D}$ plot has been demonstrated at $\mathrm{pH}$ ( 8 to 9 ) and the 340 to 360 min of irradiation time.

Figure 7 shows the photodegradation efficiency versus the photocatalyst amount from 0.5 to $3.5 \mathrm{~g} / \mathrm{L}$ and irradiation time (60-360 $\mathrm{min})$. The $\mathrm{pH}$ and $m$-cresol were kept constant 7.5 and $45.5 \mathrm{mg} / \mathrm{L}$, respectively. As shown, the efficiency was increased up to $1.3 \mathrm{~g} / \mathrm{L}$ of the photocatalyst, then it was constant up to $1.7 \mathrm{~g} / \mathrm{L}$, and finally it was decreased. Therefore, the optimum value of the photocatalyst was in the level of 1.3 to $1.7 \mathrm{~g} / \mathrm{L}$.

Figure 8 shows the efficiency of the photodegradation in different concentration of $m$-cresol ( 25 to $80 \mathrm{mg} / \mathrm{L}$ ) in level of irradiation time from 60 to $360 \mathrm{~min}$ while the $\mathrm{pH}, 7.5$, and the photocatalyst, $2 \mathrm{~g} / \mathrm{L}$, were kept constant. As the $3 \mathrm{D}$ plot demonstrates, the efficiency was continually decreasing with

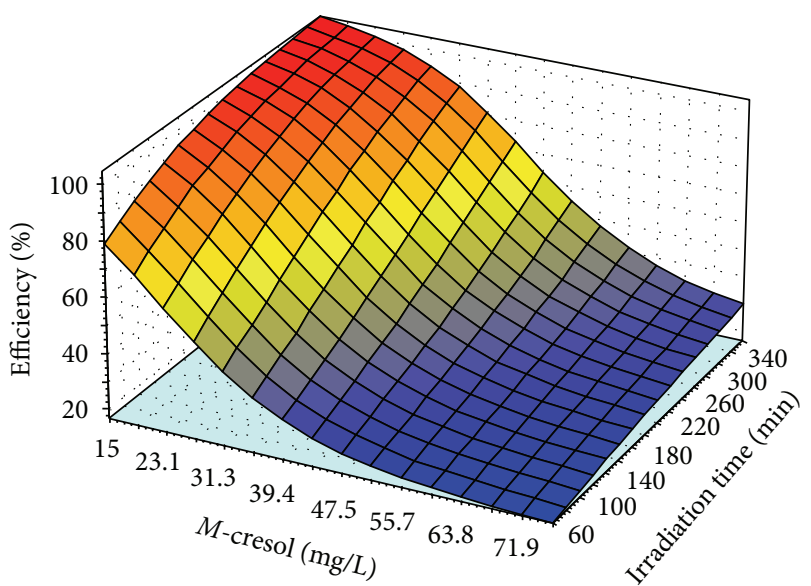

FIGURE 8: The variation of the efficiency in different concentration of $m$-cresol from 25 to $80 \mathrm{mg} / \mathrm{L}$ with irradiation time (60-360 min); the $\mathrm{pH}$ was 7.5 and amount of the photocatalyst was $2 \mathrm{~g} / \mathrm{L}$.

increasing $m$-cresol concentration. However, the removed $m$-cresol was more than $80 \%$ of $45.5 \mathrm{mg} / \mathrm{L}$ at the end of the irradiation time (340-360 min). Therefore, the maximum amount of removed $m$-cresol was $42 \mathrm{mg} / \mathrm{L}$.

The optimum value of the irradiation time was investigated by Figures 6 to 8 obtained in levels 340 to $360 \mathrm{~min}$ at the middle values of the other variables levels such as the photocatalyst, $\mathrm{pH}$, and $m$-cresol concentration. As a result of Figures 6 to 8 , the optimum levels of the effective variables were photocatalyst $(1.3-1.7 \mathrm{~g} / \mathrm{L}), \mathrm{pH}(8-9), m$-cresol $(40-$ $45 \mathrm{mg} / \mathrm{L}$ ), and irradiation time (340-360 min). To predict the optimum points of these levels, the desirable condition such as maximum $m$-cresol's concentration, minimum amount of the photocatalyst, and $\mathrm{pH}$ value at the end of the irradiation time was considered as input for the model. The model prediction included $1.3 \mathrm{~g} / \mathrm{L}$ photocatalyst, $42 \mathrm{mg} / \mathrm{L} \mathrm{m}$-cresol, $\mathrm{pH} 8$, and $360 \mathrm{~min}$ of the irradiation time while the predicted efficiency was $100 \%$. Then this condition was evaluated by further experiments and observed efficiency was $99 \%$ (almost all $m$-cresol was removed) that confirmed the improvement in comparison with other previous works [59].

4.2.2. Importance of the Effective Variables. The relative importance of the effective variables in the optimum levels was determined by the model as presented in Figure 9. As demonstrated, the greatest importance belonged to $m$-cresol (32.93\%) and $\mathrm{pH}(32.02 \%)$. However, the effects of other variables such as photocatalyst $(21.28 \%)$ and irradiation time (13.77\%) were also important for the efficiency. As a result, the selected variables were effectiveness and none of them was neglectable in this photodegradation.

4.2.3. The Model Multivariate Navigation. To navigate the photodegradation, the model (Figure 5) was used to determine the optimum levels, predict optimum points, and obtain the importance of the effective variables. The variables were initially used in a wide range and identical importance and without any considered points. The obtained information is presented by Table 2 . The optimum levels were achieved by 
TABLE 2: The results of multivariate modeling and optimization of $m$-cresol photodegradation under visible-light irradiation.

\begin{tabular}{|c|c|c|c|c|c|}
\hline Variable & $m$-cresol $(\mathrm{mg} / \mathrm{L})$ & $\mathrm{pH}$ & Photocatalyst (g/L) & Irradiation time (min) & Efficiency (\%) \\
\hline Optimum level & 40 to 45 & 8 to 9 & 1.3 to 1.7 & 340 to 460 & - \\
\hline Predicted point & 42 & 8 & 1.3 & 360 & 100 \\
\hline Verified point & 42 & 8 & 1.3 & 360 & 99 \\
\hline Importance (\%) & 32.93 & 32.02 & 21.28 & 13.77 & - \\
\hline
\end{tabular}

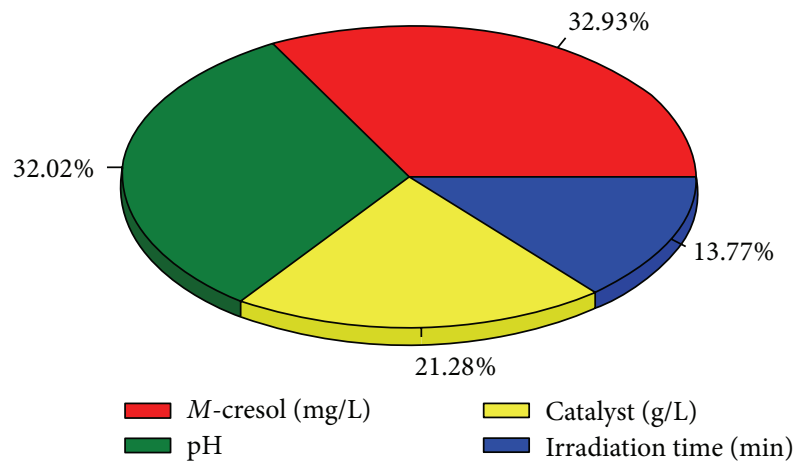

FIGURE 9: The relative importance of the photodegradation input variables such as irradiation time, $\mathrm{pH}$ amount of the photocatalyst, and $m$-cresol's concentration.

$3 \mathrm{D}$ plots in graphical vision (Figures 6 to 8 ). The optimum points of the variables in the optimized narrow levels were firstly predicted by the model and verified by further experiment with $1 \%$ error. Moreover, the model determined the relative importance of the variables which showed none of them were neglectable in this work.

\section{Conclusions}

The AAN modeling of $m$-cresol photodegradation was carried out to determination of optimum and importance values of the effective variables to achieve maximum efficiency. The photodegradation was performed in synthesis $\mathrm{Mn}$ doped $\mathrm{ZnO}$ suspension and under visible-light irradiation. The input considered effective variables of the photodegradation were irradiation, time, $\mathrm{pH}$, photocatalyst amount, and concentration of $m$-cresol while the efficiency was the only response as output. The performed experiments were designed in three data sets such as training, testing, and validation that were randomly splitted by the software's option. To obtain the optimum topologies, AAN was trained by QP, IBP, BBP, and LM algorithms for testing data set. The topologies were determined by the indicator of minimized RMSE for each algorithm. According to the indicator, the QP4-8-1, IBP-4-15-1, BBP-4-6-1, and LM-4-10-1 were selected as the optimized topologies. Among the topologies, QP-48-1 has presented the minimum RMSE and AAD as well as maximum $R^{2}$. Therefore, QP-4-8-1 was selected as final model for the photodegradation navigation. The model was used for determination of the optimum values of the effective variables to achieve the maximum efficiency by using graphical vision. The predicted optimum points of the variables were confirmed by further validated experiments. Moreover, the model predicted the relative importance of the variables which showed none of them was neglectable in this work.

\section{Conflict of Interests}

The authors declare that they have no competing interests.

\section{Acknowledgments}

The authors wish to thank Dr. Mina Abbasiyannejad for polishing and proofreading the paper. Also, they wish to thank Dr. Abdul Halim Abdullah for his help in this study.

\section{References}

[1] P. H. Gleick, The World's Water 2004-2005: The Biennial Report on Freshwater Resources, Island Press, 2004.

[2] T. Robinson, G. McMullan, R. Marchant, and P. Nigam, "Remediation of dyes in textile effluent: a critical review on current treatment technologies with a proposed alternative," Bioresource Technology, vol. 77, no. 3, pp. 247-255, 2001.

[3] M. Tamez Uddin, M. Rukanuzzaman, M. Maksudur Rahman Khan, and M. Akhtarul Islam, "Adsorption of methylene blue from aqueous solution by jackfruit (Artocarpus heteropyllus) leaf powder: a fixed-bed column study," Journal of Environmental Management, vol. 90, no. 11, pp. 3443-3450, 2009.

[4] N. Takeda and K. Teranishi, "Generation of superoxide anion radical from atmospheric organic matter," Bulletin of Environmental Contamination and Toxicology, vol. 40, no. 5, pp. 678682, 1988.

[5] O. Aviam, G. Bar-Nes, Y. Zeiri, and A. Sivan, "Accelerated biodegradation of cement by sulfur-oxidizing bacteria as a bioassay for evaluating immobilization of low-level radioactive waste," Applied and Environmental Microbiology, vol. 70, no. 10, pp. 6031-6036, 2004.

[6] M. L. Krumme and S. A. Boyd, "Reductive dechlorination of chlorinated phenols in anaerobic upflow bioreactors," Water Research, vol. 22, no. 2, pp. 171-177, 1988.

[7] O. Carp, C. L. Huisman, and A. Reller, "Photoinduced reactivity of titanium dioxide," Progress in Solid State Chemistry, vol. 32, no. 1-2, pp. 33-177, 2004.

[8] A. Fujishima, T. N. Rao, and D. A. Tryk, "Titanium dioxide photocatalysis," Journal of Photochemistry and Photobiology C: Photochemistry Reviews, vol. 1, no. 1, pp. 1-21, 2000.

[9] A. R. Khataee, V. Vatanpour, and A. R. A. Ghadim, "Decolorization of C.I. Acid Blue 9 solution by UV/Nano-TiO ${ }_{2}$, Fenton, Fenton-like, electro-Fenton and electrocoagulation processes: a comparative study," Journal of Hazardous Materials, vol. 161, no. 2-3, pp. 1225-1233, 2009. 
[10] S. K. Pardeshi and A. B. Patil, "A simple route for photocatalytic degradation of phenol in aqueous zinc oxide suspension using solar energy," Solar Energy, vol. 82, no. 8, pp. 700-705, 2008.

[11] A. Sharma, P. Rao, R. P. Mathur, and S. C. Ameta, "Photocatalytic reactions of xylidine ponceau on semiconducting zinc oxide powder," Journal of Photochemistry and Photobiology A: Chemistry, vol. 86, no. 1-3, pp. 197-200, 1995.

[12] N. Daneshvar, S. Aber, M. S. Seyed Dorraji, A. R. Khataee, and M. H. Rasoulifard, "Photocatalytic degradation of the insecticide diazinon in the presence of prepared nanocrystalline ZnO powders under irradiation of UV-C light," Separation and Purification Technology, vol. 58, no. 1, pp. 91-98, 2007.

[13] S. K. Kansal, M. Singh, and D. Sud, "Studies on $\mathrm{TiO}_{2} / \mathrm{ZnO}$ photocatalysed degradation of lignin," Journal of Hazardous Materials, vol. 153, no. 1-2, pp. 412-417, 2008.

[14] A. Akyol, H. C. Yatmaz, and M. Bayramoglu, "Photocatalytic decolorization of Remazol Red $\mathrm{RR}$ in aqueous $\mathrm{ZnO}$ suspensions," Applied Catalysis B: Environmental, vol. 54, no. 1, pp. 1924, 2004.

[15] Y. Abdollahi, A. H. Abdullah, and Z. Zainal, "Photodegradation of $\mathrm{m}$-cresol by zinc oxide under visible-light irradiation," International Journal of Chemistry, vol. 3, no. 3, pp. 31-43, 2011.

[16] Y. Abdollahil, Z. Zainal, and N. A. Yusof, "Photodegradation of o-cresol by $\mathrm{ZnO}$ under UV irradiation," Journal of American Science, vol. 7, no. 8, pp. 165-170, 2011.

[17] Y. Abdollahi, Z. Zainal, and N. A. Yusof, "Photodegradation of p-cresol by zinc oxide under visible light," International Journal of Applied Science and Technology, vol. 1, no. 5, pp. 99-105, 2011.

[18] U. I. Gaya and A. H. Abdullah, "Heterogeneous photocatalytic degradation of organic contaminants over titanium dioxide: a review of fundamentals, progress and problems," Journal of Photochemistry and Photobiology C: Photochemistry Reviews, vol. 9, no. 1, pp. 1-12, 2008.

[19] N. Vitchuli, Q. Shi, J. Nowak et al., "Multifunctional ZnO/Nylon 6 nanofiber mats by an electrospinning-electrospraying hybrid process for use in protective applications," Science and Technology of Advanced Materials, vol. 12, no. 5, Article ID 055004, 2011.

[20] F. Kayaci, C. Ozgit-Akgun, N. Biyikli, and T. Uyar, "Surfacedecorated $\mathrm{ZnO}$ nanoparticles and $\mathrm{ZnO}$ nanocoating on electrospun polymeric nanofibers by atomic layer deposition for flexible photocatalytic nanofibrous membranes," RSC Advances, vol. 3, no. 19, pp. 6817-6820, 2013.

[21] Y. Abdollahi, A. H. Abdullah, Z. Zainal, and N. A. Yusof, "Photocatalytic degradation of p-cresol by zinc oxide under UV irradiation," International Journal of Molecular Sciences, vol. 13, no. 1, pp. 302-315, 2012.

[22] Y. Abdollahi, A. Zakaria, and N. A. Sairi, "Degradation of high level $m$-Cresol by zinc oxide as photocatalyst," CLEAN-Soil, Air, Water, vol. 42, no. 9, pp. 1292-1297, 2013.

[23] B. Dindar and S. Içli, "Unusual photoreactivity of zinc oxide irradiated by concentrated sunlight," Journal of Photochemistry and Photobiology A: Chemistry, vol. 140, no. 3, pp. 263-268, 2001.

[24] F. Kayaci, C. Ozgit-Akgun, I. Donmez, N. Biyikli, and T. Uyar, "Polymer-inorganic core-shell nanofibers by electrospinning and atomic layer deposition: flexible nylon- $\mathrm{ZnO}$ core-shell nanofiber mats and their photocatalytic activity," ACS Applied Materials and Interfaces, vol. 4, no. 11, pp. 6185-6194, 2012.

[25] C.-C. Chen, "Degradation pathways of ethyl violet by photocatalytic reaction with $\mathrm{ZnO}$ dispersions," Journal of Molecular Catalysis A: Chemical, vol. 264, no. 1-2, pp. 82-92, 2007.
[26] B. Pandey, S. Ghosh, P. Srivastava, D. K. Avasthi, D. Kabiraj, and J. C. Pivin, "Synthesis and characterization of Ni-doped $\mathrm{ZnO}$ : a transparent magnetic semiconductor," Journal of Magnetism and Magnetic Materials, vol. 320, no. 24, pp. 3347-3351, 2008.

[27] D. Chu, Y.-P. Zeng, and D. Jiang, "Synthesis and growth mechanism of $\mathrm{Cr}$-doped $\mathrm{ZnO}$ single-crystalline nanowires," Solid State Communications, vol. 143, no. 6-7, pp. 308-312, 2007.

[28] Y. R. Park and K. J. Kim, "Optical and electrical properties of Ti-doped $\mathrm{ZnO}$ films: observation of semiconductor-metal transition," Solid State Communications, vol. 123, no. 3-4, pp. 147-150, 2002.

[29] Y. Abdollahi, A. H. Abdullah, Z. Zainal, and N. A. Yusof, "Synthesis and characterization of manganese doped $\mathrm{ZnO}$ nanoparticles," International Journal of Basic \& Applied Sciences, vol. 11, no. 4, pp. 62-69, 2011.

[30] J. Moser, M. Grätzel, and R. Gallay, "Inhibition of electron-hole recombination in substitutionally doped colloidal semiconductor crystallites," Helvetica Chimica Acta, vol. 70, no. 6, pp. 1596$1604,1987$.

[31] E. Borgarello, J. Kiwi, M. Grätzel, E. Pelizzetti, and M. Visca, "Visible light induced water cleavage in colloidal solutions of chromium-doped titanium dioxide particles," Journal of the American Chemical Society, vol. 104, no. 11, pp. 2996-3002, 1982.

[32] W. Choi, A. Termin, and M. R. Hoffmann, "The role of metal ion dopants in quantum-sized $\mathrm{TiO}_{2}$ : correlation between photoreactivity and charge carrier recombination dynamics," The Journal of Physical Chemistry, vol. 98, no. 51, pp. 1366913679, 1994.

[33] Y. Abdollahi, A. H. Abdullah, U. I. Gaya, Z. Zainal, and N. A. Yusof, "Enhanced photodegradation of o-cresol in aqueous $\mathrm{Mn}(1 \%)$-doped ZnO suspensions," Environmental Technology, vol. 33, no. 10, pp. 1183-1189, 2012.

[34] Y. Abdollahi, A. H. Abdullah, U. I. Gaya et al., "Photocatalytic degradation of 1,4-Benzoquinone in aqueous $\mathrm{ZnO}$ dispersions," Journal of the Brazilian Chemical Society, vol. 23, no. 2, pp. 236240, 2012.

[35] A. R. Khataee and M. B. Kasiri, "Artificial neural networks modeling of contaminated water treatment processes by homogeneous and heterogeneous nanocatalysis," Journal of Molecular Catalysis A: Chemical, vol. 331, no. 1-2, pp. 86-100, 2010.

[36] Y. Abdollahi, A. Zakaria, A. H. Abdullah et al., "Semi-empirical study of ortho-cresol photo degradation in manganese-doped zinc oxide nanoparticles suspensions," Chemistry Central Journal, vol. 6, no. 1, article 88, 2012.

[37] Y. Abdollahi, A. Zakaria, K. A. Matori et al., "Interactions between photodegradation components," Chemistry Central Journal, vol. 6, no. 1, article 100, 2012.

[38] S. Weisberg, Applied Linear Regression, John Wiley \& Sons, 2005.

[39] D. Salari, N. Daneshvar, F. Aghazadeh, and A. R. Khataee, "Application of artificial neural networks for modeling of the treatment of wastewater contaminated with methyl tert-butyl ether (MTBE) by $\mathrm{UV} / \mathrm{H}_{2} \mathrm{O}_{2}$ process," Journal of Hazardous Materials, vol. 125, no. 1-3, pp. 205-210, 2005.

[40] S. Aber, A. R. Amani-Ghadim, and V. Mirzajani, "Removal of $\mathrm{Cr}(\mathrm{VI})$ from polluted solutions by electrocoagulation: modeling of experimental results using artificial neural network," Journal of Hazardous Materials, vol. 171, no. 1-3, pp. 484-490, 2009.

[41] S. Göb, E. Oliveros, S. H. Bossmann, A. M. Braun, R. Guardani, and C. A. O. Nascimento, "Modeling the kinetics of a photochemical water treatment process by means of artificial 
neural networks," Chemical Engineering and Processing: Process Intensification, vol. 38, no. 4-6, pp. 373-382, 1999.

[42] P. Calza, V. A. Sakkas, A. Villioti et al., "Multivariate experimental design for the photocatalytic degradation of imipramine: determination of the reaction pathway and identification of intermediate products," Applied Catalysis B: Environmental, vol. 84, no. 3, pp. 379-388, 2008.

[43] V. K. Pareek, M. P. Brungs, A. A. Adesina, and R. Sharma, "Artificial neural network modeling of a multiphase photodegradation system," Journal of Photochemistry and Photobiology A: Chemistry, vol. 149, no. 1-3, pp. 139-146, 2002.

[44] N. Shivaraman and R. Pandey, "Characterization and biodegradation of phenolic wastewater," Journal of Indian Association for Environmental Management, vol. 27, pp. 12-15, 2000.

[45] M. Callahan, M. Slimak, N. Gbel et al., "Water related environmental fate of 120 priority pollutants," Tech. Rep. EPA-4401479-029a, b, United States Environmental Protection Agency, NTIS, Washington, DC, USA, 1979.

[46] Y. Abdollahi, A. H. Abdullah, A. Zakaria, Z. Zainal, H. R. F. Masoumi, and N. A. Yusof, "Photodegradation of p-cresol in aqueous $\mathrm{Mn}(1 \%)$-doped $\mathrm{ZnO}$ suspensions," Journal of Advanced Oxidation Technologies, vol. 15, no. 1, pp. 146-152, 2012.

[47] M. A. Fox and M. T. Dulay, "Heterogeneous photocatalysis," Chemical Reviews, vol. 93, no. 1, pp. 341-357, 1993.

[48] M. Sanchooli and M. G. Mighaaddam, "Evaluation of acidity constants of anthraquinone derivatives in methanol/water mixtures using real quantum descriptors," Journal of Chemical Engineering of Japan, vol. 45, no. 6, pp. 373-379, 2012.

[49] M. G. Moghaddam and M. Khajeh, "Comparison of response surface methodology and artificial neural network in predicting the microwave-assisted extraction procedure to determine zinc in fish muscles," Food and Nutrition, vol. 2, pp. 803-808, 2011.

[50] X. Song, A. Mitnitski, C. MacKnight, and K. Rockwood, "Assessment of individual risk of death using self-report data: an artificial neural network compared with a frailty index," Journal of the American Geriatrics Society, vol. 52, no. 7, pp. 1180-1184, 2004.

[51] A. Amani, P. York, H. Chrystyn, B. J. Clark, and D. Q. Do, "Determination of factors controlling the particle size in nanoemulsions using artificial neural networks," European Journal of Pharmaceutical Sciences, vol. 35, no. 1-2, pp. 42-51, 2008.

[52] A. Ghaffari, H. Abdollahi, M. R. Khoshayand, I. S. Bozchalooi, A. Dadgar, and M. Rafiee-Tehrani, "Performance comparison of neural network training algorithms in modeling of bimodal drug delivery," International Journal of Pharmaceutics, vol. 327, no. 1-2, pp. 126-138, 2006.

[53] G. D. Garson, "Interpreting neural-network connection weights," AI Expert, vol. 6, no. 4, pp. 46-51, 1991.

[54] F. Despagne and D. L. Massart, "Neural networks in multivariate calibration," Analyst, vol. 123, no. 11, pp. 157R-178R, 1998.

[55] J. Zhang, A. J. Morris, E. B. Martin, and C. Kiparissides, "Prediction of polymer quality in batch polymerisation reactors using robust neural networks," Chemical Engineering Journal, vol. 69, no. 2, pp. 135-143, 1998.

[56] Y. Abdollahi, A. Zakaria, M. Abbasiyannejad et al., "Artificial neural network modeling of $p$-cresol photodegradation," Chemistry Central Journal, vol. 7, no. 1, article 96, 2013.

[57] B. B. Mandelbrot, "How long is the coast of Britain? Statistical self-similarity and fractional dimension," Science, vol. 156, no. 3775, pp. 636-638, 1967.
[58] A. Li, H. Li, K. Li, and Z. Gu, "Applications of neural networks and genetic algorithms to CVI processes in carbon/carbon composites," Acta Materialia, vol. 52, no. 2, pp. 299-305, 2004.

[59] Y. Abdollahi, A. H. Abdullah, Z. Zainal, and N. A. Yusof, "Degradation of m-cresol with $\mathrm{Mn}$ doped $\mathrm{ZnO}$ nanoparticles under visible light irradiation," Fresenius Environmental Bulletin, vol. 21, no. 2, pp. 256-262, 2012. 

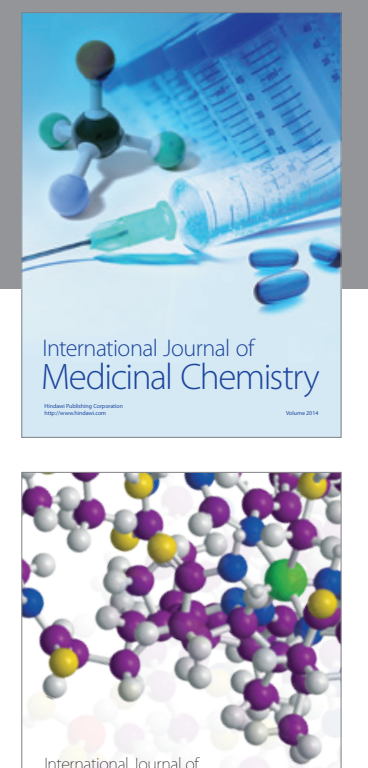

\section{Carbohydrate} Chemistry

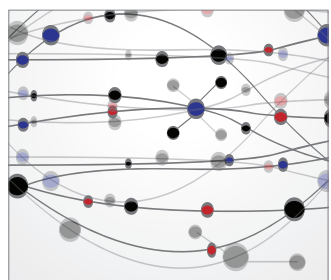

The Scientific World Journal
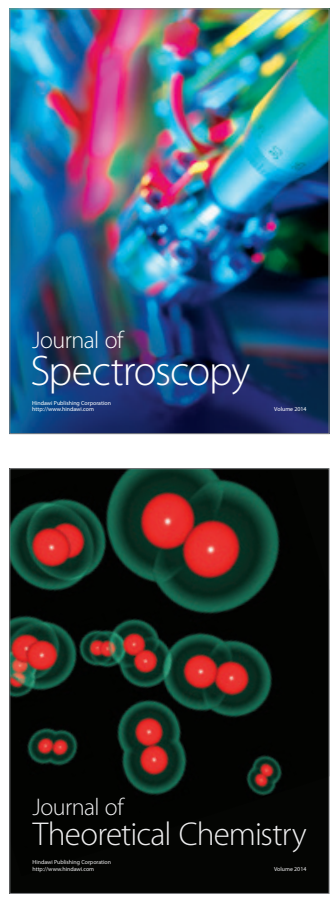
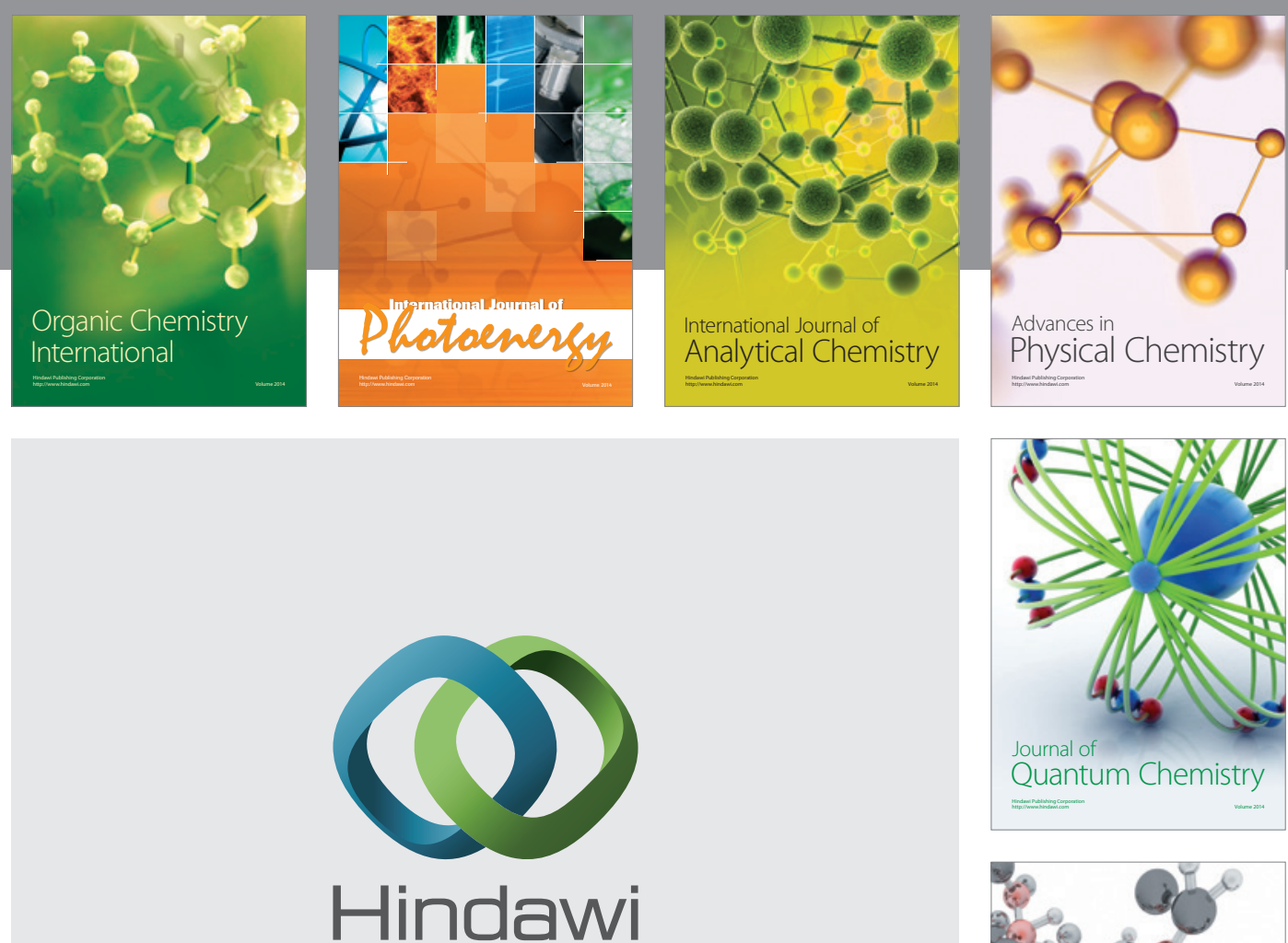

Submit your manuscripts at

http://www.hindawi.com

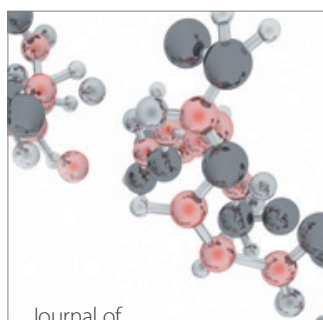

Analytical Methods

in Chemistry

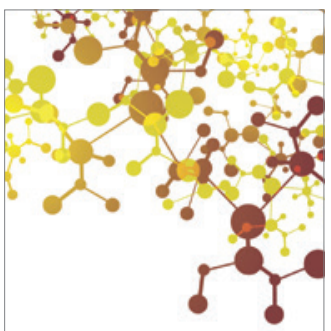

Journal of

Applied Chemistry

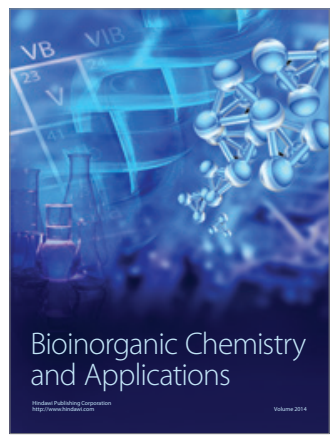

Inorganic Chemistry
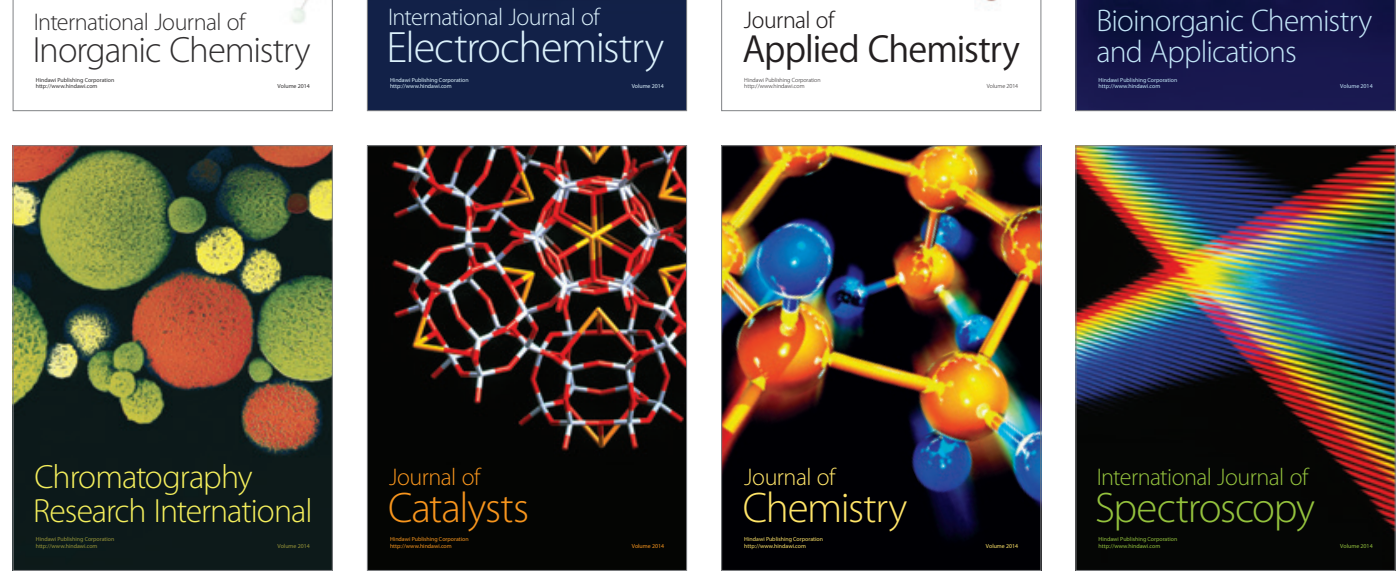